\title{
Changes in Cytoskeletal Gene Expression Affect the Composition of Regenerating Axonal Sprouts Elaborated by Dorsal Root Ganglion Neurons in vivo
}

\author{
Monica M. Oblinger, ${ }^{1}$ Rick A. Szumlas, ${ }^{1}$ Johnson Wong, ${ }^{1}$ and Francis J. Liuzzi ${ }^{2}$ \\ 'Department of Cell Biology and Anatomy, Chicago Medical School, North Chicago, Illinois 60064, and 'Department of \\ Anatomy, Eastern Virginia Medical School, Norfolk, Virginia 23501
}

\begin{abstract}
The effect of a change in neurofilament (NF) and tubulin gene expression on the elongation of axonal sprouts by adult rat sensory neurons was examined. Distal sciatic nerve crush axotomy was used to initiate changes in cytoskeletal gene expression in lumbar dorsal root ganglion (DRG) neurons. In situ hybridization of DRG neurons with ${ }^{35}$ S-labeled CDNA probes revealed a significant reduction in the level of mRNAs for the low-molecular weight-NF protein and a significant increase in the level of beta tubulin mRNAs by 2 weeks after axotomy. A novel modification of the axonal transport paradigm was used to examine the biochemical composition of the regenerating axons formed by primed and unprimed DRG neurons. Primed neurons (which had sustained a crush axotomy of the distal sciatic nerve 2 weeks earlier) and unprimed (normal) neurons were labeled by microinjection of ${ }^{35} \mathrm{~S}$-methionine and then stimulated to regenerate axons by a crush located very close to the DRG. In this paradigm, axonal sprouts that formed after the proximal crush axotomy incorporated radiolabeled, slow axonally transported proteins as they elongated. Fluorographs of SDS-PAGE revealed that the regenerating axonal sprouts of primed DRG cells incorporated and conveyed significantly less labeled NF protein than did the regenerating axons of unprimed DRG neurons. Electron microscopy revealed that the regenerating axonal sprouts of primed DRG cells contained numerous microtubules but very few identifiable NFs compared with the regenerating sprouts of unprimed DRG neurons. In keeping with the hypothesis that NFs have a primary role in determining axonal caliber, our morphometric analyses of electron micrographs also revealed that the caliber of regenerating axonal sprouts of primed DRG cells was significantly smaller than that of unprimed cells. Since the regenerating axons of primed DRG cells elongate at a significantly faster rate than those of unprimed neurons, our findings suggest that a down-regulation of NF gene expression may play a major role in the efficiency of axonal regeneration.
\end{abstract}

\footnotetext{
Received Oct. 7, 1988; revised Jan. 5, 1989; accepted Jan. 20, 1989.

We gratefully acknowledge the excellent technical assistance of Ben Sanchez in this work. This work was supported by NIH grant NS-21571 and a grant from the Schweppe Foundation to M.M.O. and by NIH grant NS-24309 to F.J.L.

Correspondence should be addressed to Dr. Monica M. Oblinger, Department of Cell Biology and Anatomy, Chicago Medical School, 3333 Green Bay Rd., North Chicago, IL 60064.

Copyright (c) 1989 Society for Neuroscience $0270-6474 / 89 / 082645-09 \$ 02.00 / 0$
}

An axotomizing crush of peripheral mammalian axons initiates the process of axonal regeneration. During this process, finecaliber axonal sprouts emerge from the parent stump of axon which remains attached to the neuron cell body, and the new sprouts elongate distally. Provided that environmental conditions are supportive, regeneration continues until the new axons elongate sufficiently to reconnect with appropriate target tissues. The final stage of the regeneration process involves the radial growth of the new axons. The cytoskeletal polymers, microfilaments, microtubules, and neurofilaments (NFs), are well known to have a central role in the regeneration process since they provide the basis for structure, motility, and final stability of the new axons. A highly vectorial process supplies the cytoskeletal elements needed for axonal regeneration. Transcription of cytoskeletal genes and translation of cytoskeletal proteins occur only in the neuron cell body (Lasek et al., 1973). The cytoskeletal polymers are assembled shortly after synthesis (Black et al., 1986) and then exported to the axon, where slow axonal transport conveys them through the parent axon (Lasek and Hoffman, 1976; Brady and Lasek, 1982). Recent studies have demonstrated that the slowly transported cytoskeletal proteins of the parent axon are recruited into the fine-caliber axonal sprouts at the injury site and that the ongoing mechanisms of slow axonal transport continue in the regenerating axonal sprouts to enable the elongation of the new axons (McQuarrie and Lasek, 1989).

Studies of rat dorsal root ganglion (DRG) neurons have indicated that peripheral axotomy induces changes in the levels of $m$ RNAs for the NF proteins and tubulins (Hoffman et al., 1987; Wong and Oblinger, 1987; Goldstein et al., 1988; Hoffman and Cleveland, 1988). Peripheral axotomy of DRG cells is also known to result in changes in the synthesis and subsequent axonal transport of NF and tubulin proteins (Oblinger and Lasek, 1985, 1988; Greenberg and Lasek, 1988). The slow transport changes that occur in peripheral mammalian neurons after axotomy include reduced levels of NF proteins and increased levels and rates of tubulin transport (Hoffman and Lasek, 1980; Oblinger, 1985; Oblinger and I asek, 1985, 1988). Studies of the conditioning lesion phenomenon in a variety of neurons have suggested that changes in the expression and utilization of cytoskeletal proteins in axotomized neurons may contribute to a more efficient regenerative process (reviewed in McQuarrie, 1983, 1984). For example, regenerating axons elaborated by DRG neurons that have been primed by a previous distal axotomy made 2 weeks earlier elongate at a significantly faster rate than normal (Forman et al., 1981; McQuarrie, 1984; 
Oblinger and Lasek, 1984). The cascade of changes initiated by axotomy are postulated to contribute to the conditioning lesion phenomenon of an augmented axonal growth rate.

In the present study, we hypothesized that regenerating axonal sprouts elaborated by conditioned neurons differ from those claborated by unprimed neurons with respect to their cytoskeletons. We explored this hypothesis using the well-characterized system of L5 DRG neurons of rats following unilateral crush of the sciatic nerve. First, we examined the changes in mRNA levels for the NF and tubulin proteins in DRG neurons $14 \mathrm{~d}$ after distal peripherai axotomy by quantitative in situ hybridization. Second, we labeled protein synthesis in normal DRG neurons and in DRG neurons $14 \mathrm{~d}$ after distal peripheral axotomy and subsequently examined how labeled cytoskeletal proteins were utilized in regenerating axonal sprouts by employing a novel modification of the axonal transport paradigm. In this new paradigm, the peripheral axons of conditioned or primed DRG neurons (those that had sustained a distal sciatic nerve crush 2 weeks earlier) and those of normal, unprimed DRG neurons were crushed very close to the DRG (3-4 mm; test axotomy site) immediately after protein synthesis was labeled in these cells by injection of ${ }^{35} \mathrm{~S}$-methionine. As regeneration ensued after the test axotomy under the 2 conditions, the radiolabeled cytoskeletal proteins that were recruited into, and slowly transported in, the newly regrowing axonal sprouts were assessed using quantitative SDS-PAGE/fluorography. Finally, we compared the ultrastructure of the axonal sprouts elaborated by primed and unprimed DRG neurons using morphometric analyses of electron micrographs. We present our findings that primed DRG neurons that have down-regulated levels of NF and up-regulated levels of tubulin mRNAs elaborate axonal sprouts that incorporate and axonally transport lower levels of NF proteins relative to unprimed DRG neurons. A direct morphological consequence of these changes that we document here is that the axonal sprouts of primed DRG neurons have a significantly smaller caliber and a cytoskeleton characterized by numerous microtubules and substantially fewer NFs than do the regenerating axons elaborated by unprimed DRG neurons.

\section{Materials and Methods}

Animals. Adult male Sprague-Dawley rats (Harlan Sprague Dawley, Indianapolis, IN) weighing 300-350 gm were used for all experiments. All animals were acquired, cared for, and surgically handled in accordance with the guidelines specified in the $N I H$ Guide for the Care and Use of Laboratory Animals. For surgical procedures, animals were anesthetized with Chloropent ( $3 \mathrm{ml} / \mathrm{kg}$, i.p; Fort Dodge Laboratories, Fort Dodge, IA); for scheduled kills, animals were decapitated under ether anesthesia.

In situ hybridization experiments. The sciatic nerves of adult rats were crushed unilaterally at 50-60 $\mathrm{mm}$ from the L5 DRG (priming crush site). The lesion consisted of 3 successive $30 \mathrm{sec}$ crushes with \#5 Dumont forceps, a method that reliably axotomizes all axons in the sciatic nerve (Oblinger and Lasek, 1984, 1988). The experimental and contralateral control L5 ganglia were removed 2 weeks after the distal axotomy and fixed by immersion in $4 \%$ paraformaldehyde for $2 \mathrm{hr}$. The ganglia were cmbedded in paraffin, sectioned at $10 \mu \mathrm{m}$, and hybridized with ${ }^{35} \mathrm{~S}$ labeled cDNAs as described previously (Wong and Oblinger, 1987). In all cases, slides from the entire experimental and control series of ganglia were hybridized together to minimize variability. The probes used for hybridization included NFL cDNA (Lewis and Cowan, 1985) and $\beta$-tubulin cDNA (entire clone RBT1; Bond et al., 1984). Northern blots corffirmed that the NFL probe hybridized to 2.5 and $4.0 \mathrm{~kb}$ mRNAs; the $\beta$-tubulin probe hybridized mainly with a $1.8 \mathrm{~kb}$ mRNA and more weakly with 3.0 and $2.5 \mathrm{~kb}$ mRNAs. The hybridization with multiple tubulin mRNAs when using the entire RBT1 probe was expected due to the conservation of the coding region of the $\beta$-tubulin genes (Bond et al., 1984). The use of this probe allowed us to examine overall $\beta$-tubulin mRNA changes. Slides were developed after $2-4 \mathrm{~d}$ exposure and lightly counterstained with cresyl violet. The density of silver grains over large DRG neurons ( $\left.>1000 \mu \mathrm{m}^{\prime}\right)$ in which a clearly defined nucleus and nucleolus was present was analyzed using a computer-based imageanalysis system as described previously (Wong and Oblinger, 1987).

Axonal transport experiments. The L5 DRG and a $6 \mathrm{~mm}$ stretch of the peripheral L5 nerve was exposed unilaterally, and $2 \mu \mathrm{l}$ saline containing $1 \mathrm{mCi}$ of ${ }^{35} \mathrm{~S}$-methionine (New England Nuclear) was microinjected into the midpoint of the DRG. The isotope was injected using a glass micropipette over a period of $10 \mathrm{~min}$. The DRG was then flushed with saline, and immediately thereafter the peripheral L5 nerve was crushed 3 consecutive times for $30 \mathrm{sec}$ with a $\# 5$ Dumont forceps at 3$4 \mathrm{~mm}$ from the ganglion (test crush site). In one group of rats, the distal sciatic nerve ( $50-60 \mathrm{~mm}$ from the L5 DRG-priming crush site) was crushed 2 weeks prior to the isotope injection/test crush procedure. In each condition (primed and unprimed), 4 rats were prepared. Animals were killed $12 \mathrm{~d}$ following injection/test crush, and the L5 DRG with the attached peripheral nerve were removed and frozen on dry ice. The nerves were cut into consecutive $2 \mathrm{~mm}$ segments and homogenized in $200 \mu \mathrm{l}$ of SUB $(0.5 \%$ SDS, $8 \mathrm{~m}$ urea, $2 \%$ beta-mercaptoethanol). A 100 $\mu \mathrm{l}$ volume of each sample was subjected to SDS-PAGE/fluorography as described previously (Oblinger, 1987).

Morphometric studies of regenerating axonal sprouts. A test crush of the peripheral L5 nerve (3-4 $\mathrm{mm}$ from the $L 5$ DRG) was made in several normal rats and in several rats that had sustained a priming crush of the distal sciatic nerve 2 weeks earlier (as described above). However, for the morphological studies, the surgical procedure was more involved than for biochemical studies since all other axons besides the L 5 sensory fibers in the sciatic nerve had to be removed. Thus, the L4 and L6 peripheral nerves and the L5 ventral root were cut and ligated with $\# 6$ silk suture immediately prior to making the test crush of the L5 peripheral nerve. In both primed and unprimed groups of animals, rats were killed $12 \mathrm{~d}$ after the test crush and intracardially perfused with $1.2 \%$ paraformaldehyde, $2 \%$ glutaraldehyde in $120 \mathrm{~mm}$ sodium phosphate buffer containing $8 \%$ sucrose. The peripheral L5 nerve was removed, and the nerve segments located 6-9 mm distal to the test crush site were prepared for electron microscopy. The tissue was processed through $2 \%$ osmium, $0.5 \%$ uranyl acetate, and embedded in Maraglas resin (Polysciences, Warrington, PA). Thin sections of regenerating axons were cut, examined with the electron microscope, and photographed. For quantitation, 100 identified axonal sprouts from both the primed and unprimed conditions were randomly selected from photomicrographs and the cross-sectional areas determined using a computer-based image-analysis system.

\section{Results}

Changes in the levels of NF and tubulin mRNAs in axotomized DRG neurons measured by in situ hybridization

In situ hybridization of histological sections of DRG neurons with labeled cDNAs was used to examine the effects of periphcral axotomy on NF and tubulin mRNA levels. Visual comparisons of the autoradiograms of DRG neurons that had sustained a distal sciatic nerve crush (50-60 $\mathrm{mm}$ from the L5 DRG) 2 weeks earlier with those of control DRG neurons indicated that the level of NFL mRNA was reduced, while the level of $\beta$-tubulin mRNAs was increased in axotomized DRG cells (Fig. 1). The examples shown are randomly selected neurons from the various conditions. In all ganglia, some of the axotomized neurons exhibited a substantial change in grain density, while other neurons showed more modest alterations. Quantitation of grain densities over the large-sized (>1000 $\left.\mu \mathrm{m}^{2}\right)$ DRG neurons using a computer-assisted image-analysis system was done to determine the mean change in NFL and $\beta$-tubulin mRNA levels after axotomy. Significantly fewer silver grains per unit cell area $(p<0.05)$ were found over large axotomized DRG neurons than over contralateral control neurons in the hybridization experiments with the NFL cDNA probe (Fig. 2). Conversely, in experiments with the $\beta$-tubulin cDNA probe, the mean grain density over axotomized DRG neurons was signif- 

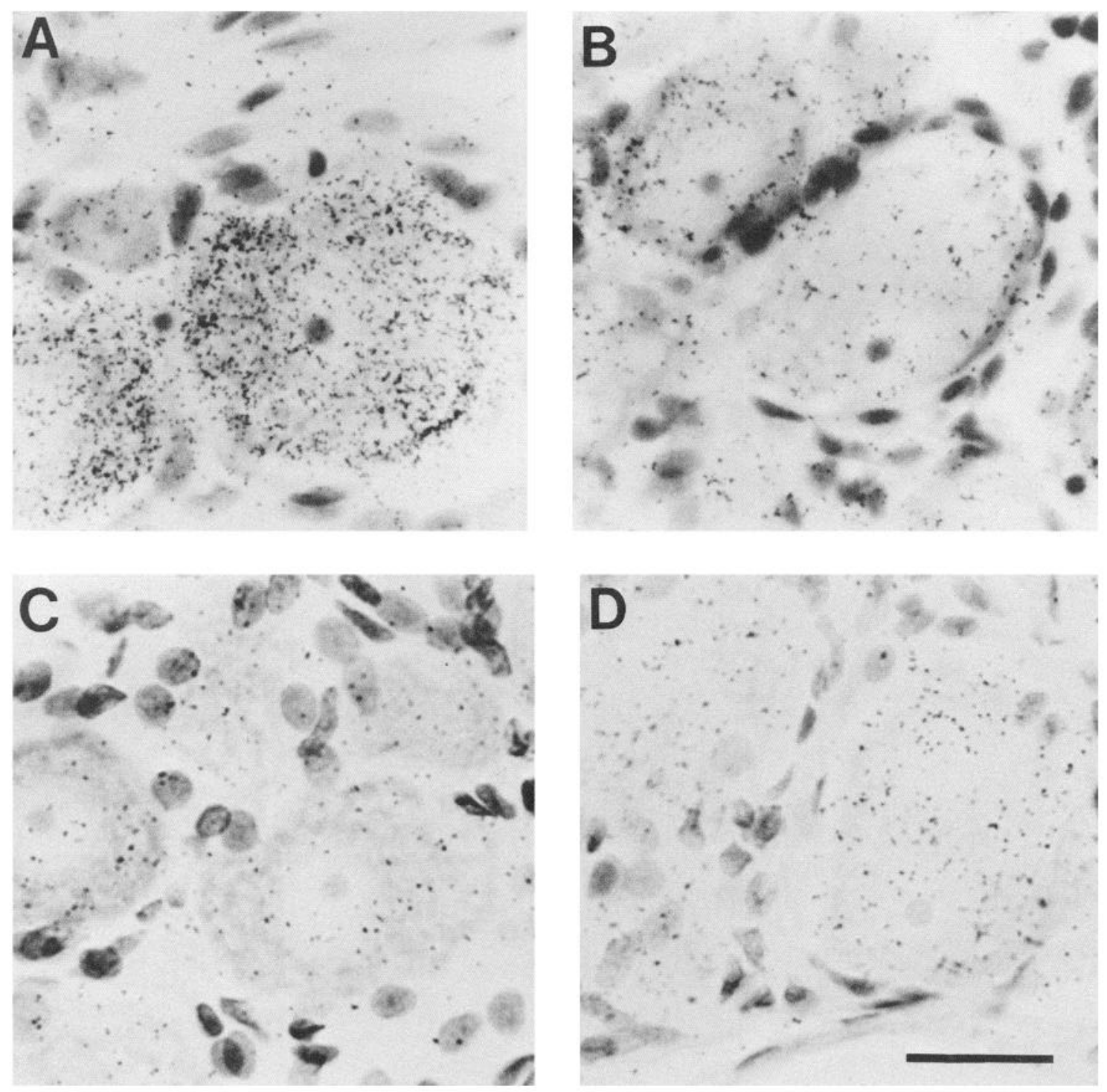

Figure 1. Localization of NFL and $\beta$-tubulin mRNAs within sensory neurons by in situ hybridization with ${ }^{35}$-labeled cDNA probes. The autoradiograms of $(A)$ control DRG neurons and $(B)$ axotomized DRG neurons (2 weeks after distal sciatic nerve crush) were hybridized with NFL cDNA and exposed for $4 \mathrm{~d}$. In the lower panels, control $(C)$ and 2 week postaxotomy $(D)$ DRG neurons were hybridized with $\beta$-tubulin cDNA and exposed for $2 \mathrm{~d}$. Control neurons are from the contralateral L5 DRG of the operated animals in each case. The neurons shown were randomly selected from the various conditions. Note the presence of chromatolytic neurons in the axotomized condition. Scale bar, $25 \mu \mathrm{m}$.

icantly higher $(p<0.05)$ than that over control neurons (Fig. 2). These findings confirm previous results obtained using quantitative in situ hybridization, which indicated a down-regulation of NFL mRNA levels in axotomized DRG neurons (Hoffman et al., 1987; Wong and Oblinger, 1987) and also provide support for recent findings on changes in the levels of specific types of $\beta$-tubulin mRNAs in axotomized neurons (Hoffman and Cleveland, 1988).

\section{Axonal transport of cytoskeletal proteins in regenerating axonal sprouts}

Axonal transport of NF and tubulin proteins in regenerating axonal sprouts of DRG neurons was examined by SDS-PAGE/ fluorography. Proteins synthesized by L5 DRG neurons were radiolabeled by microinjection of ${ }^{35} \mathrm{~S}$-methionine into the ganglion and, immediately thereafter, the peripheral L5 nerve was crushed at a distance of 3-4 $\mathrm{mm}$ from the L5 ganglion (test crush site). In this paradigm, new axonal sprouts elaborated by the DRG neurons in response to the test crush grow distally from the parent stump of axon (proximal to the crush site) and necessarily incorporate radiolabeled proteins synthesized by the L5 DRG neurons as they elongate. In the "unprimed" condition, protein labeling was done in normal, uninjured DRG neurons. In the "primed" condition, a crush lesion of the distal sciatic nerve (50-60 $\mathrm{mm}$ from the L5 DRG) was done 2 weeks prior to the labeling/test crush procedure and, thus, protein labeling was done on axotomized neurons. In both conditions, the test crush immediately followed the labeling and the regenerating axonal sprouts were harvested $12 \mathrm{~d}$ later for analysis by SDSPAGE/fluorography.

Fluorographs illustrated major differences in the axonally transported proteins present in sprouts of unprimed and primed 


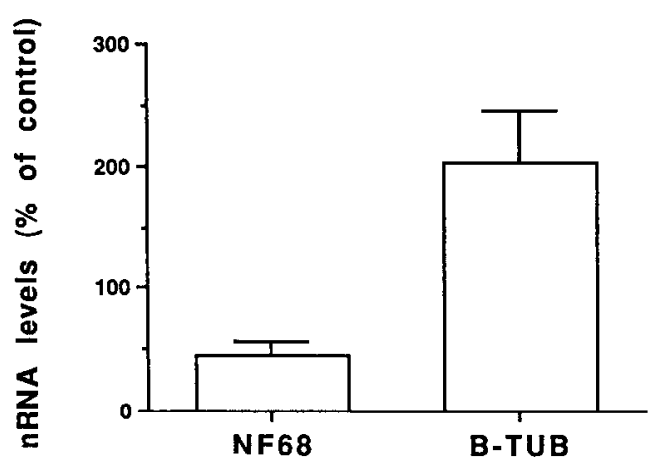

Figure 2. Quantitation of NF and tubulin mRNA changes in axotomized DRG neurons by in situ hybridization. Grain densities (number of silver grains $/ \mu \mathrm{m}^{2}$ of cell area) were determined for 25-50 neurons per DRG. In each case, the contralateral DRG served as the control. Only large neurons $\left(>1000 \mu \mathrm{m}^{2}\right)$ in which a clearly defined nucleus and nucleolus were present were used for grain counting. The average experimental/control grain densities are plotted as percentages; the SEM is shown. $n=5$ experimental and 5 contralateral control ganglia for NF68 (NFL), and $n=3$ experimental and contralateral ganglia for $\beta$-tubulin.

DRG neurons (Fig. 3). The position of the crush site in both primed and unprimed systems was readily discernible in fluorographs by the pile-up of radioactive proteins in the parent axons proximal to the crush sitc; distal to this sitc, labcled proteins that had entered the regenerating sprouts were observed. The major labeled proteins present in the regenerating axons of unprimed neurons were the NF triplet proteins, tubulins and actin (Fig. $3 A$ ). In contrast, very little labeled NF protein was present in the axonal sprouts of primed neurons; the major proteins in these sprouts were the tubulins and actin (Fig. $3 B$ ). Another difference was that the tubulin region of the gels from the sprouts of unprimed neurons consistently contained 3 bands while that from sprouts of unprimed cells only resolved 2 major bands (Fig. 3).

The front of the labeled cytoskeletal proteins in Figure 3 is estimated to roughly correspond to the position of the wavefront of the main population of regrowing sensory fibers in both conditions. The rate of elongation of regenerating axons is known to be different in primed and unprimed DRG neurons. The fastest growing (leading) sensory axons in the primed condition are known to elongate at $5.5 \mathrm{~mm} / \mathrm{d}$, while leading axons of unprimed DRG cells grow at $4.4 \mathrm{~mm} / \mathrm{d}$ (Oblinger and Lasek, 1984). However, it is very important to note that the bulk of sensory axons in the nerve do not grow at the rate of the few leading axons but instead form a wide wave that advances considerably more slowly (around $2 \mathrm{~mm} / \mathrm{d}$; Oblinger and Lasek, 1984). Our previous studies have shown that priming of DRG cells accelerates the rate of growth of the main population of regrowing sensory axons, as well as that of the leading axons (Oblinger and Lasek, 1984). The fluorographs of the transport experiments shown in Figure 3 were exposed to reveal the main population of regenerating axons and, thus, the protein profiles are representative of the composition of the bulk of the regenerating sprouts that grow more slowly than do the leading few pioneer axons.

Quantitation of the axonal transport data was done by excising gel pieces using the fluorographs as guides and determining their radioactivity. The mean ratios of radioactivity in NFL and tubulin in consecutive $2 \mathrm{~mm}$ segments of nerve that contained re- generating sprouts were determined. This procedure revealed that significantly lower ratios $(p<0.01)$ of labeled NFL protein/ tubulin were present in regenerating sprouts of primed than in unprimed DRG neurons (Fig. 4). Some minor variability in the ratios along segments of individual nerves were observed, but no significance was attributed to this. When the labeled NF protein present in regenerating sprouts was normalized to total labeled axonal protein rather than tubulin, a significant reduction in the amount of $\mathrm{NF}$ protein transport was also found in sprouts of primed and unprimed DRG neurons (data not shown).

Scveral other obscrvations from the axonal transport cxpcriments were significant. First, it was of interest to find that the rate of advance of the labeled NF protein front in the sprouts (Fig. 3) was quite similar to that found in intact DRG axons in previous studies (Lasek et al., 1983; Oblinger and Lasek, 1988). While careful kinetic studies of NF transport in the sprouts have not yet been done, this observation suggested that the rate of transport of NFs in the sprouts is not different from that in the parent axons. Second, it was determined that all 3 of the NF proteins entered regenerating axons at the parent axon-sprout junction (Fig. 3). Thus, regenerating axons of adult DRG neurons incorporated "mature" NFs instead of the immature NFs expressed in newly growing axons during development. While the developmental issue is not yet entirely settled, several lines of evidence suggest that during initial axonal development, an immature form of NF, comprised of only the low- and middlemolecular-weight NF subunits, may be present in axons (Willard and Simon, 1983; Pachter and Liem, 1984; Carden et al., 1987). Our present findings indicate that NFs do not reorganize into the "immature" form at the injury site and, thus, probably do not disassemble and then reassemble prior to entering the regenerating sprouts.

\section{Electron microscopy of axonal sprouts elaborated by primed and unprimed $D R G$ neurons}

The finding that regenerating axons elaborated by primed DRG neurons contained significantly less labeled NF protein in slow axonal transport than those from unprimed DRG neurons suggested that the morphology of axonal sprouts produced under the 2 conditions was different. To directly examine this, quantitative morphometric analyses of electron microscopic (EM) sections of regenerating axons in the 2 conditions were done. For the EM studies, all axons that contribute to the sciatic nerve except for the peripheral sensory fibers of the L5 DRG neurons were removed just prior to the test crush of the L5 nerve. As in the axonal transport experiments, the primed condition involved making a distal crush of the sciatic nerve 2 weeks prior to the test crush surgery. At $12 \mathrm{~d}$ after the test crush, axonal sprouts from primed and unprimed DRG cells were harvested an equal distance from the test crush site and examined by electron microscopy.

The ultrastructure of axonal sprouts from unprimed and primed DRG neurons was strikingly different (Fig. 5). One consistent difference was that the regenerating axons of primed neurons contained very few identifiable NFs and relatively more microtubules than those of unprimed DRG neurons. Quantitative analysis of the axonal sprouts from the 2 conditions revealed that the regenerating axonal sprouts of unprimed DRG cells had a broader range of cross-sectional areas, with more axons reaching larger sizes, than those of primed DRG cells (Fig. 6). The mean cross-sectional area of regenerating axonal sprouts from primed DRG cells $\left(0.41 \mu \mathrm{m}^{2}\right)$ was significantly 

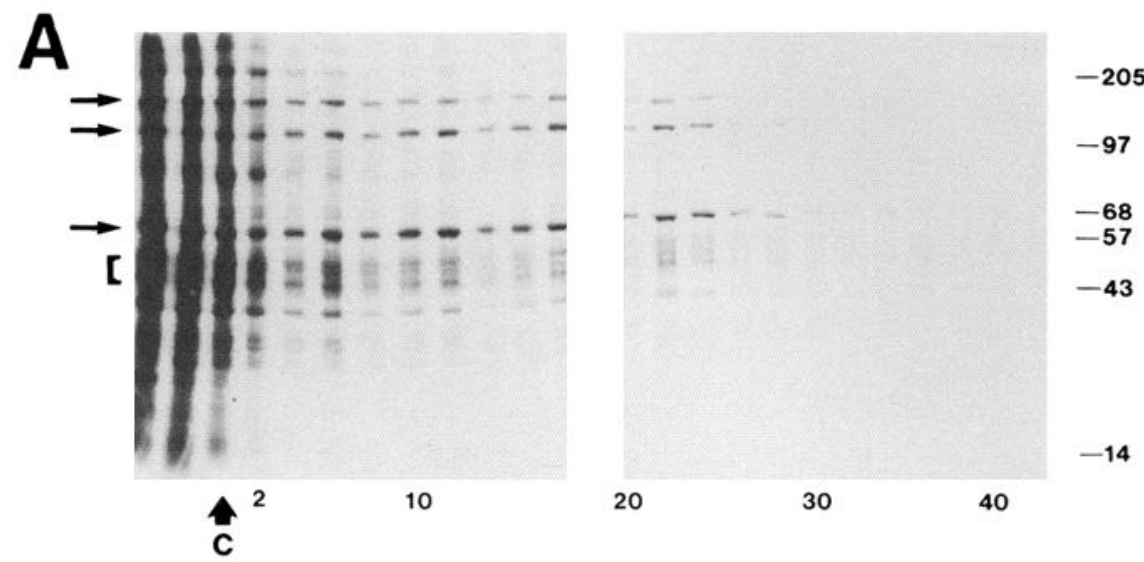

Figure 3. Axonal sprouts of primed DRG neurons convey less labeled NF protein by slow axonal transport than those of unprimed DRG neurons. Fluorographs of SDS-PAGE-separated proteins present in regenerating axonal sprouts $12 \mathrm{~d}$ after microinjecting L5 DRG with ${ }^{35}$ S-methionine and crushing the peripheral L5 nerve $4 \mathrm{~mm}$ from the ganglion (test crush) are shown. $A$, Unprimed system: Normal L5 DRG system. $B$, Primed system: A crush lesion of the distal sciatic nerve $(50-60 \mathrm{~mm}$ from the L5 DRG-priming crush site) was made 2 weeks prior to the isotope

B

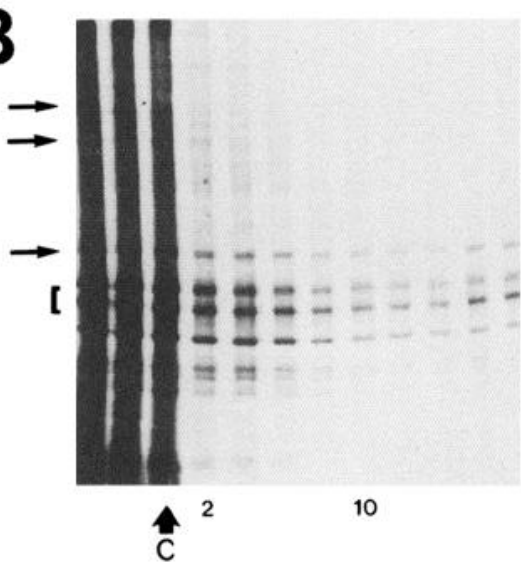

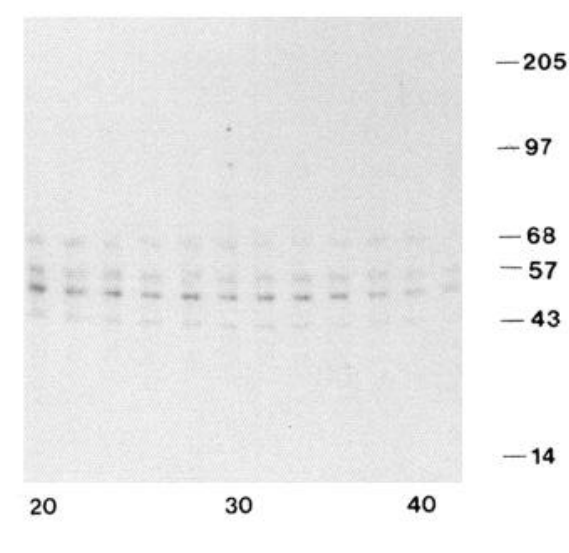
injection/test crush procedure. Consecutive $2 \mathrm{~mm}$ samples of peripheral axons were solubilized and loaded onto successive gel lanes. The first gel lane at left in both panels corresponds to the L5 DRG; subsequent lanes are axons either proximal to or distal to the test crush site (indicated by $C$ and arrow). Numbers at the bottom of lanes indicate distances (in $\mathrm{mm}$ ) from the test crush site. Molecular-weight standards are indicated on the far right side of each panel in kilodaltons $(\mathrm{kDa})$. The neurofilament (NF) triplet proteins $(200,145$, $68 \mathrm{kDa}: \mathrm{H}, \mathrm{M}$, and L) are indicated by large arrows; the tubulins are indicated by brackets. smaller $(p<0.01)$ than that of sprouts from unprimed DRG cells $\left(1.33 \mu \mathrm{m}^{2}\right)$. These findings indicated that the changes in expression and axonal transport of cytoskeletal proteins in primed DRG neurons resulted in morphologically different axonal sprouts that were elaborated by these cells in response to a testing axotomy. Specifically, primed DRG cells produced smaller-caliber regenerating axons containing fewer NFs than did unprimed DRG cells.

\section{Discussion}

A new paradigm for examining the composition of regenerating axons and evaluating the effects of experimental manipulations

The paradigm of labeling regenerating axons by axonal transport enables the biochemical analysis of axonal sprouts without the complicating contribution of non-neuronal cells (which are unlabeled). Since the paradigm of labeling regenerating sprouts by axonal transport will undoubtedly be useful in exploring the effects of various types of experimental manipulations on axonal growth, it is important to review some of the considerations that enter into such experiments when the focus is the axonal cytoskeleton. First, it is important to consider the location of the axotomy site in relation to the dynamics of the slowly transported axonal cytoskeleton. When axonal regeneration is initiated a considerable distance (centimeters) from the cell body,

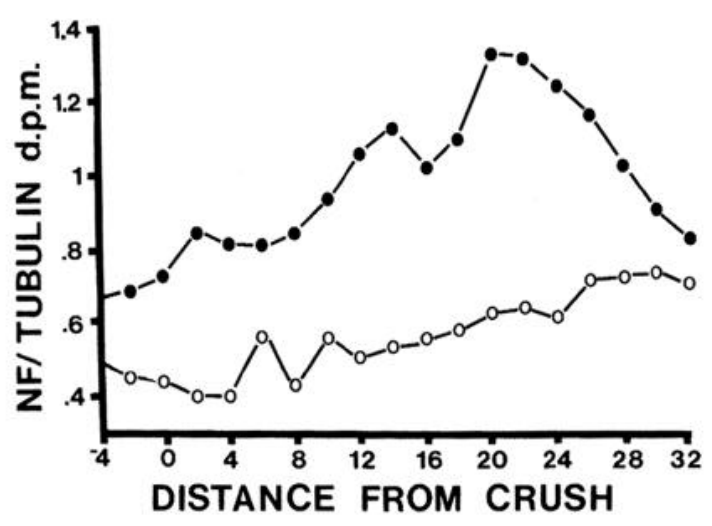

Figure 4. Quantitation of cytoskeletal protein transport in regenerating axons of unprimed and primed DRG neurons. The regions of gels containing NFL and $\beta$-tubulin were excised using the fluorographs as templates, dissolved in $30 \%$ hydrogen peroxide, and counted. The mean ratios of NF/tubulin radioactivity in successive $2 \mathrm{~mm}$ segments of nerve are plotted for normal DRG axons (closed circles) and primed DRG axons (open circles). Plots represent the mean of 4 separate experiments for each condition. The crush position is indicated on the $x$-axis by 0 distance; $-4 \mathrm{~mm}$ is the DRG sample and positive numbers represent $2 \mathrm{~mm}$ segments of regenerating sprouts. 

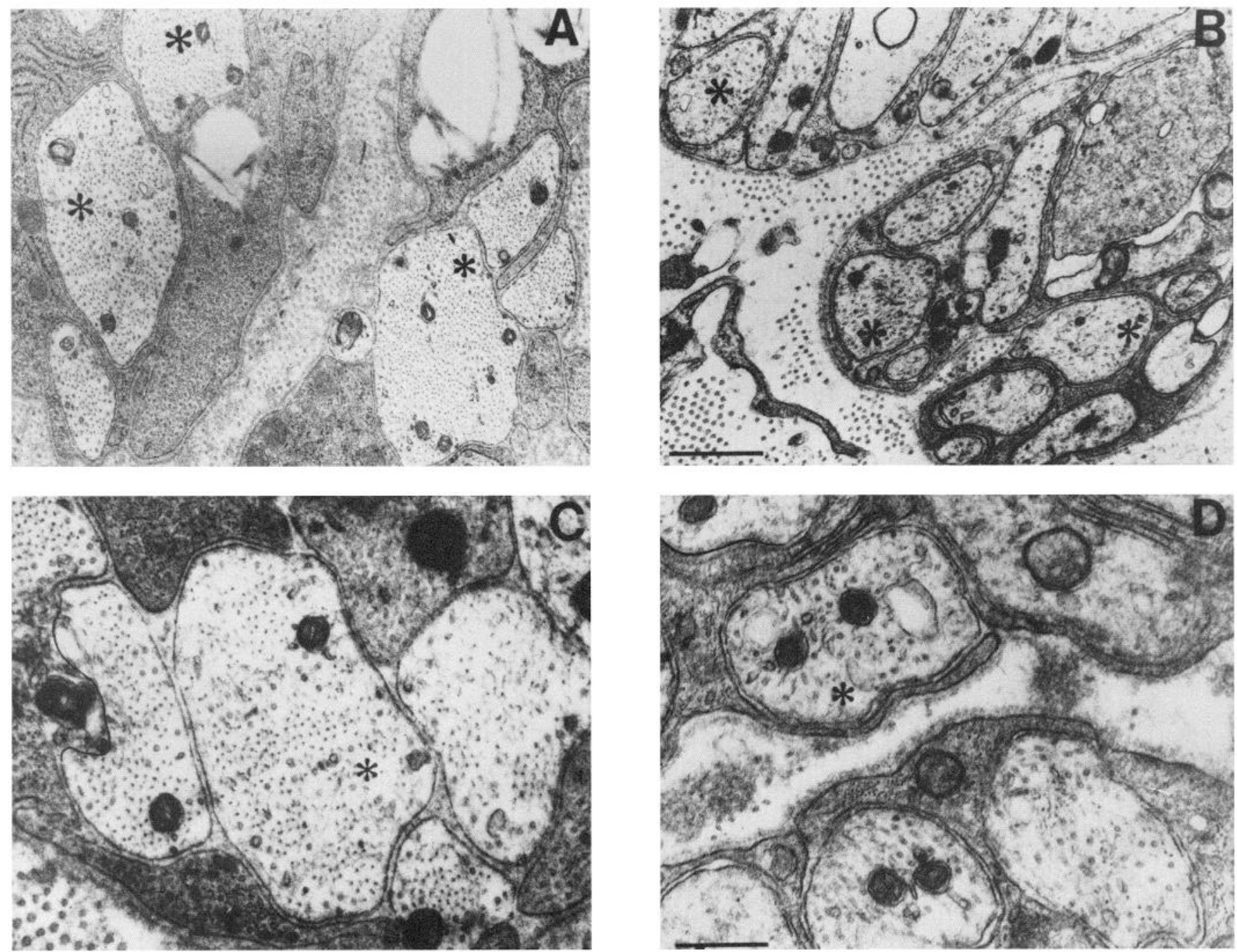

Figure 5. Comparison of the ultrastructure of regenerating sprouts of unprimed and primed DRG neurons. The electron micrographs in $A$ and $C$ (higher magnification) show axonal sprouts from unprimed DRG cells; those in $B$ and $D$ show regenerating sprouts from primed DRG cells. All micrographs were taken from thin sections of the sciatic nerve 6-9 mm distal to the test crush site $12 \mathrm{~d}$ after the test crush. Several axons are indicated by asterisks in each panel. Note the larger caliber and the more numerous NFs in the sprouts of unprimed neurons compared with primed neurons. Further details about the experimental preparations are presented in Materials and Methods. Scale bars: $A$ and $B, 0.2 \mu \mathrm{m} ; C$ and $D$, $0.4 \mu \mathrm{m}$.

the cytoskeletal elements needed for the formation of the sprouts will be recruited from existing materials already in transit in the parent axon (Weiss and Hiscoe, 1948). This is evidenced by the fact that axonal regrowth begins shortly after axotomy, while the supply of newly synthesized cytoskeletal proteins takes days or weeks to reach the axotomy site by slow transport (Oblinger and Lasek, 1984, 1988). Thus, with distal axotomy, the cytoskeletal proteins already in transit in the axons (which had been synthesized a considerable time earlier) will determine the composition of the regenerating axons, and it is necessary to prelabel the axons days to weeks prior to initiating regeneration. In a recent study, ventromotor axons were prelabeled with the $\mathrm{SCb}$ component of slow transport (which conveys actin, some of the axonal tubulin, and many other proteins) and the distal sciatic nerve was crushed just ahead of the labeled $\mathrm{SCb}$ front (McQuarrie and Lasek, 1989). That study demonstrated that $\mathrm{SCb}$ proteins of the parent axon were recruited into the axonal sprouts at the axotomy site and that $\mathrm{SCb}$ transport continued with similar kinetics in the regenerating axons as in the parent axons.
Because of the distal location of the axotomy site and the temporal parameters of the experiments, that study did not provide information about the transport of NFs (which move more slowly in SCa) in regenerating axons. The distal injury paradigm combined with prelabeling the axons has provided some important information about sprout formation, but because of the necessary temporal parameters, it is clearly not the optimal paradigm for examining the effects of changes in the expression of cytoskeletal proteins on axonal growth.

In the present study we opted to use a very proximal axotomy site and to label protein synthesis in the neuron cell bodies immediately before initiating axonal sprout formation. When regeneration is initiated very close to the neuronal cell body, changes in ongoing protein synthesis will have an almost immediate effect on the composition of regrowing axons since the products of cell body synthesis have to traverse only a very short parent stump before being recruited into the nascent axonal sprouts. The use of a proximal axotomy site eliminates the need to prelabel the neurons days to weeks before the crush and the 
effect of normal levels of gene expression versus the effect of a definable change in the level of gene expression on the formation of axonal sprouts can thus be evaluated. This approach permitted us to examine the consequences of a quantifiable change in NF and tubulin mRNA level and synthesis in the DRG cell bodies on axonal sprout formation. At the outset of our experiments it was known that one effect of a priming axotomy of $D R G$ cells was an acceleration of the rate of axonal elongation if the axons were injured in a second time within a 2 week interval (Oblinger and Lasek, 1984). The present study was initiated with the hypothesis that axonal sprouts of DRG neurons primed by a prior axotomy differed with respect to their cytoskeletons from those elaborated by normal or unprimed DRG neurons. The following sections discuss the data obtained in support of this hypothesis in our study.

Morphological differences in axonal sprouts from primed vs unprimed neurons are the result of alterations in the vectorial process that supplies the axonal cytoskeleton

The results of the present study have shown that regenerating axons of previously injured DRG neurons are dramatically different with respect to their cytoskeletons from those elaborated by unprimed DRG neurons. The sprouts of primed neurons have a smaller average cross-sectional area and have a cytoskeleton characterized by a paucity of NFs compared with the sprouts elaborated by unprimed DRG neurons. These differences appear to be a direct consequence of the vectorial process that supplies the cytoskeletal polymers to the axon. This vectorial process has the following main stages: transcription, translation, assembly, export, and slow axonal transport. We will consider how alterations at each stage could potentially influence the structure of a regenerating axon.

The first stage of the vectorial process is the transcription of cytoskeletal genes into mRNAs. Since this is the first step in the cascade, it is clear that changes at this level could have major effects on the composition of the cytoskeleton. Unfortunately, with available technology, it has not yet been possible to directly determine whether transcriptional changes occur in neurons after axotomy. However, using in situ hybridization of histological sections with cDNA probes, we have provided evidence that large DRG neurons contain significantly reduced levels of NFL mRNAs and significantly increased levels of $\beta$-tubulin mRNAs 2 weeks after peripheral axotomy. Obviously, the level of a given mRNA in a cell could be determined by either transcriptional changes or changes in mRNA stability, and it will be of great importance in the future to distinguish between these possibilitles. The present findings of changes in NF and tubulin mRNA levels in axotomized DRG neurons are in agreement with those of several earlier studies (Hoffman et al., 1987, Wong and Oblinger, 1987, Goldstein et al., 1988, Hoffman and Cleveland, 1988) and support the idea that a major factor underlying the priming lesion effect on sprout morphology is the level of NF and tubulin gene expression.

Translation of cytoskeletal proteins is another major step in the vectorial process that links genes to structure. Previous studies in DRG cells as well as other types of neurons have provided strong evidence that the synthesis of NF proteins is significantly reduced after axotomy (Oblinger and Lasek, 1985, 1988; Greenberg and Lasek, 1988). Tubulin synthesis has been shown to increase or not change depending on experimental conditions (Oblinger and Lasek, 1985, 1988; Greenberg and Lasek, 1988). The overwhelming majority of cytoskeletal proteins synthesized

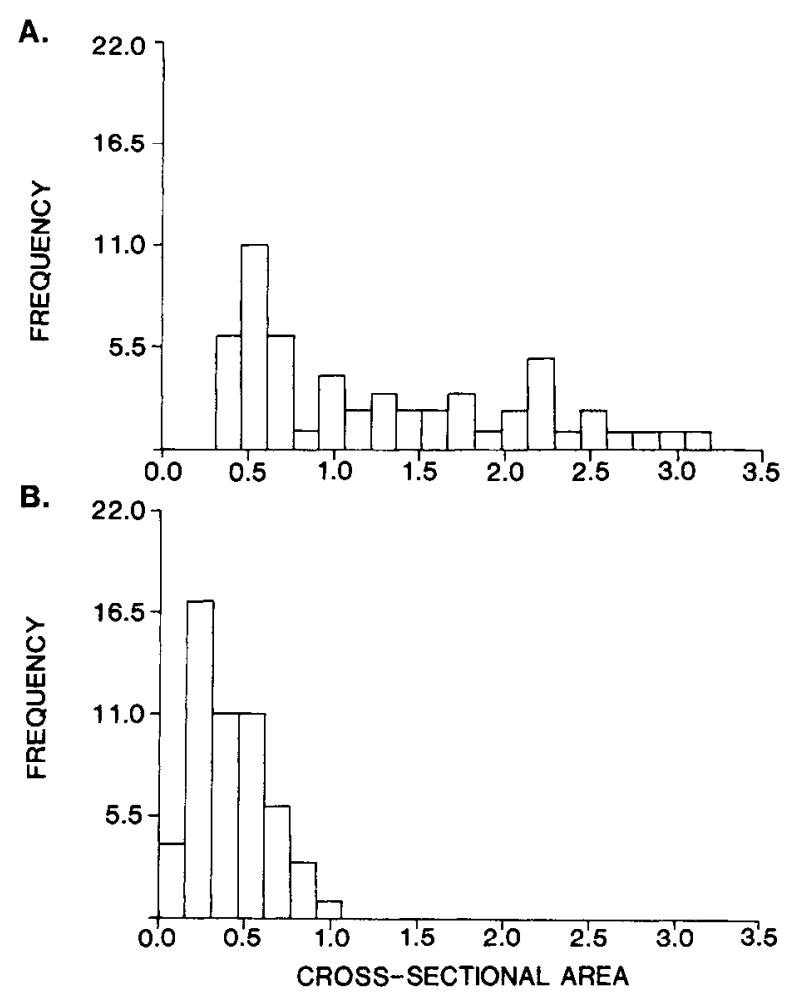

Figure 6. Frequency histograms of cross-sectional areas of regenerating axonal sprouts from unprimed $(A)$ and primed $(B)$ DRG neurons. The percentage of axonal sprouts in various size categories $\left(\mu \mathrm{m}^{2}\right)$ are plotted; data were obtained by measuring the cross-sectional areas of 100 randomly selected axons from electron micrographs of each condition using a computer-based image-analysis system. The mean cross-sectional area of regenerating axonal sprouts from primed DRG cells was $0.41 \mu \mathrm{m}^{2}$; that of sprouts from unprimed DRG cells was $1.33 \mu \mathrm{m}^{2}$. All measurements of axonal sprouts were taken from the sciatic nerve $6-9 \mathrm{~mm}$ distal to the test crush site $12 \mathrm{~d}$ after the test crush. As in all other experiments, the primed condition refers to a distal lesion $(50-60 \mathrm{~mm}$ from the L5 DRG) of the sciatic nerve made 2 wecks prior to the test crush. Further experimental details are described in Materials and Methods.

in DRG cells are destined for export into the massive axonal compartments, and, thus, synthesis is a critical determinant of the amount of cytoskeletal polymers supplied to the axon.

Evidence indicates that assembly of cytoskeletal proteins into polymer in neurons is tightly linked temporally to translation (Black et al., 1986; Black and Smith, 1988). For example, 90\% of the NF proteins are assembled within $15 \mathrm{~min}$ of synthesis and $75 \%$ of the tubulin is assembled within $2 \mathrm{hr}$ (Black and Smith, 1988). NFs apparently are very stable polymers, and once they are assembled in the cell body, they remain in the polymer form during transport (Lasek and Hoffman, 1976; Morris and Lasek, 1982). Microtubules also appear to be assembled largely in the cell body, but the microtubulc system of the axon is somewhat more dynamic, consisting of stable polymers, metastable polymers, and free subunits that interact during the process of microtubule transport in axons (reviewed in Lasek, 1988). Assembly is clearly an important step in cytoskeletal supply to the axons since unassembled NFs and tubulin do not appear to be transported in the subunit form. At present, no studies of cytoskeletal assembly under axotomy conditions have been reported.

The next intermediate stage in the vectorial process that supplies the cytoskeleton, export of the cytoskeleton from the soma 
into the axon, is still poorly understood. Several studies of axotomized neurons using electron microscopy or immunocytochemical techniques have suggested that NFs may accumulate in the soma after axotomy (Price and Porter, 1972; Moss and Lewkowicz, 1983; Drager and Hofbauer, 1984; Goldstein et al., 1987). In addition, evidence suggesting that delayed release of NFs into axons and that selective export of NFs into the 2 axons of DRG cells occur after axotomy has also been obtained recently (Oblinger and Lasek, 1988). The relationship between these more complex mechanisms involved in the supply of cytoskclcton to axons and the actual lcvels of NFs and microtubules in axons remains to be clarified by further study.

The final pathway of expression of the cytoskeletal genes is slow axonal transport. A great deal of information about slow transport in normal peripheral axons as well as in intact axonal regions of injured mammalian neurons is available (Lasek and Hoffman, 1976; Black and Lasek, 1980; Hoffman and Lasek, 1980; Wujek and Lasek, 1983; Oblinger and Lasek, 1985, 1988). NFs are transported exclusively with the SCa subcomponent of slow transport, and a consistent observation in studies of slow transport in intact axonal regions of axotomized neurons is that NF protein levels in SCa are markedly reduced. Several studies have documented a morphological consequence of this reduction in the amount of NF protein transport, namely, a somatofugal reduction in the caliber of the parent axons (Hoffman et al., 1984, 1985, 1987, 1988). The findings of the present study extend these observations by directly examining the consequences of a change in the level of axonally transported cytoskeletal proteins on the structure of the axonal sprouts themselves. Our new findings demonstrate the importance of the expression and axonal transport of NFs in defining the caliber of regenerating axonal sprouts.

\section{The composition of the cytoskeleton within regenerating sprouts may be an important determinant of the rate of regeneration}

The final manifestation of the conditioning or priming lesion phenomenon in the DRG system is an acceleration of the axonal elongation rate that occurs when axons are injured a second time within an interval of 1-3 weeks following the first axotomy (reviewed in McQuarrie, 1983, 1984; Oblinger and Lasek, 1984). In rat DRG neurons, a priming lesion accelerates the elongation rate of the leading axons by $25 \%$ and also increases the rate of growth of the main population of regenerating sensory axons that lag behind the pioneer axons (Oblinger and Lasek, 1984). Can the molecular composition of the cytoskeleton influence axonal growth rate and do changes in the composition of the cytoskeleton after a priming axotomy underlie the change in axonal growth rate?

The idea of a relationship between growth rate and the composition of the cytoskeleton has been suggested by several lines of earlier research. For example, during development when the axonal growth rate is significantly faster than in the adult, the rate of cytoskeletal protein transport is faster and the slow component of axonal transport is characterized by far less NF protein than in the adult (Hoffman et al., 1983; Willard and Simon, 1983; Pickett and Oblinger, 1986). On a gross level, the rate of slow axonal transport (the $\mathrm{SCb}$ subcomponent in particular) is known to correlate with the rate of axonal elongation (Wujek and Lasek, 1983). In axotomized neurons, the rate of transport of $\mathrm{SCb}$ proteins such as tubulin and actin has been shown to increase in the parent axons (McQuarrie and Grafstein, 1982;
McQuarrie, 1983, 1984; Oblinger, 1985). It is of great interest that accelerated tubulin transport in SCb correlates with a reduction in the level of NF transport in injured axons (Hoffman and Lasek, 1980; Oblinger, 1985; Oblinger and Lasek, 1985, 1988).

On a more molecular level, axonal growth rate is a complex phenomenon that depends both on environmental conditions (substrate adhesivity) and on intrinsic mechanisms (polymer elongation and polymer translocation) that must be coordinated to influence the rate of axonal elongation (Lasek, 1988). Sliding of cytoskcletal polymers relative to each other has been suggested as the motile model for slow transport (Lasek, 1986). In that model, NFs represent the "drag" on the system since they are the slowest moving, most numerous, and bulkiest of the cytoskeleial systems. We propose that the increased rate of transport of other cytoskeletal elements such as microtubules and actin filaments which keep pace with the advancing growth cones (Yamada et al., 1971; McQuarrie, 1985) after priming axotomy is a consequence of reduced numbers of NFs. A reduction in the number of NFs with their extensive side arms in the axonal cytoplasm may enable more efficient sliding of the other polymers such as microtubules and microfilaments and, thus, a faster overall rate of supply of these elements to advancing axons. This could be a result of reduced numbers of molecular interactions between NFs and microtubules or simply a result of reduced steric hindrance to the transport of other axonal elements in conditions when the number of bulky NF polymers is reduced. In either case, a reduction in NF number could ultimately result in a faster rate of supply of microtubules and actin filaments to support a faster rate of advance of regenerating sprouts. The present study lends support to this hypothesis by demonstrating that axons of primed DRG neurons which grow at a faster rate than normal have an altered cytoskeletal composition that is dominated by a vastly reduced number of NFs.

\section{Conclusion}

The hypothesis that the expression of NF genes is a primary determinant of axonal caliber has been proposed and examined under a variety of different conditions in recent years. In the present study we have provided strong support for this hypothesis using a powerful new paradigm that focuses on regenerating sprouts formed by DRG neurons. We have demonstrated that the regenerating axonal sprouts elaborated by DRG neurons which have down-regulated levels of NF gene expression are of smaller caliber and contain fewer NFs than those elaborated by unprimed DRG neurons that maintain normal levels of NF expression. We propose that the reduction in NFs may be a major factor in the accelerated elongation rate of regenerating axons in conditioned neurons.

\section{References}

Black, M. M., and R. J. Lasek (1980) Slow components of axonal transport: Two cytoskeletal networks. J. Cell Biol. 86: 616-623.

Black, M. M., and W. Smith (1988) Regional differentiation of the neuronal cytoskeleton with an Appendix: Diffusion of proteins in the neuron cell body - mathematical approximations and computer simulations. In Intrinsic Determinants of Neuronal Form and Function, R. J. Lasek and M. M. Black, eds., pp. 463-486, Alan R. Liss, New York.

Black, M. M., P. Keyser, and E. Sobel (1986) Interval between the synthesis and assembly of cytoskeletal proteins in cultured neurons. J. Neurosci. 6: 1004-1012.

Bond, J. F., G. S. Robinson, and S. R. Farmer (1984) Differential 
expression of two neural cell-specific $\beta$-tubulin mRNAs during rat brain development. Mol. Cell Biol. 4: 1313-1319.

Brady, S. T., and R. J. Lasek (1982) The slow components of axonal transport: Movements, compositions and organization. In Axoplasmic Transport, D. G. Weiss, ed., pp. 206-217, Springer-Verlag, Berlin.

Carden, M. J., J. Q. Trojanowski, W. W. Schlaepfer, and V. M.-Y. Lee (1987) Two-stage expression of neurofilament polypeptides during rat neurogenesis with early establishment of adult phosphorylation patterns. J. Neurosci. 7: 3489-3504.

Drager, U. C., and A. Hofbauer (1984) Antibodies to heavy neurofilament subunit detect a subpopulation of damaged ganglion cells in retina. Nature 309: 624-626.

Forman, D. S., I. G. McQuarrie, B. Grafstein, and D. L. Edwards (1981) Effect of a conditioning lesion on axonal regeneration and recovery of function. In Lesion-Induced Neuronal Plasticity in Sensorimotor Systems, H. J. Flohr and W. Precht, eds., pp. 103-113, SpringerVerlag, Berlin.

Goldstein, M. E., H. S. Cooper, J. Bruce, M. J. Carden, V. M.-Y. Lee, and W. W. Schlaepfer (1987) Phosphorylation of neurofilament proteins and chromatolysis following transection of rat sciatic nerve. $J$. Neurosci. 7: 1586-1594.

Goldstein, M. E., S. R. Weiss, R. A. Lazzarini, P. S. Shneidman, J. F. Lees, and W. W. Schlaepfer (1988) mRNA levels of all three neurofilament proteins decline following nerve transection. Mol. Brain Res. 3: 287-292.

Greenberg, S. E., and R. J. Lasek (1988) Neurofilament protein synthesis in DRG neurons decreases more after peripheral axotomy than after central axotomy. J. Neurosci. 8: 1739-1746.

Hoffman, P. N., and D. W. Cleveland (1988) Neurofilament and tubulin expression recapitulates the developmental program during axonal regeneration: Induction of a specific $\beta$-tubulin isotype. Proc. Natl. Acad. Sci. USA 85: 4530-4533.

Hoffman, P. N., and R. J. Lasek (1980) Axonal transport of the cytoskeleton in regenerating motor neurons: Constancy and change. Brain Res. 202: 317-333.

Hoffman, P. N., J. W. Griffin, and D. L. Price (1984) Control of axonal caliber by neurofilament transport. J. Cell Biol. 99: 705-714.

Hoflman, P. N., G. W. Thompson, J. W. Griflin, and D. L. Price (1985) Changes in neurofilament transport coincide temporally with alteration in the caliber of axons in regenerating motor fibers. J. Cell Biol. 101: 1332-1340.

Hoffman, P. N., D. W. Cleveland, J. W. Griffin, P. W. Landes, N. J. Cowan, and D. L. Price (1987) Neurofilament gene expression: A major determinant of axonal caliber. Proc. Natl. Acad. Sci. USA 84: 3472-3476.

Hoffman, P. N., E. H. Koo, N. A. Muma, J. W. Griffin, and D. L. Price (1988) Role of neurofilaments in the control of axonal caliber in myelinated nerve fibers. In Intrinsic Determinants of Neuronal Form and Function, R. J. Lasek and M. M. Black, eds., pp. 389-402, Liss, New York.

Lasek, R. J. (1986) Polymer sliding in axons. J. Cell Sci. (Suppl.) 5: 161-179.

Lasek, R. J. (1988) Studying the intrinsic determinants of neuronal form and function. In Intrinsic Determinants of Neuronal Form and Function, R. J. Lasek and M. M. Black, eds., pp. 3-58, Liss, New York.

Lasek, R. J., and P. N. Hoffman (1976) The neuronal cytoskeleton, axonal transport and axonal growth. In Cell Motility, Vol. C: Microtubules and Related Proteins, R. Goldman, T. Pollard, and J. Rosenbaum, eds., pp. 1021-1051, Cold Spring Harbor Press, Cold Spring Harbor, NY.

Lasek, R. J., C. Dabrowski, and R. Nordlander (1973) Analysis of axoplasmic RNA from invertebrate giant axons. Nature 244: 162 165.

Lasek, R. J., M. M. Oblinger, and P. F. Drake (1983) The molecular biology of neuronal geometry: The expression of neurofilament genes influences axonal diameter. Cold Spring Harbor Symp. Quant. Biol. 48: 731-744.

Lewis, S. A., and N. J. Cowan (1985) Genetics, evolution and expression of the $68,000-\mathrm{mol}-\mathrm{wt}$ neurofilament protein: Isolation of a cloned cDNA probe. J. Cell Biol. 100: 843-850.

McQuarrie, I. G. (1983) Role of the axonal cytoskeleton in the regencrating ncrvous systcm. In Nerve, Organ and Tissue Regeneration: Research Perspectives, F. J. Seil, ed., pp. 51-86, Academic, New York.

McQuarrie, I. G. (1984) Effect of a conditioning lesion on axonal transport during regeneration: The role of slow transport. In Axonal Transport in Neuronal Growth and Regeneration, J. Elam and P. Cancalon, eds., pp. 185-209, Plenum, New York.

McQuarrie, I. G. (1985) Effect of a conditioning lesion on axonal sprout formation at nodes of Ranvier. J. Comp. Neurol. 231: 239249.

McQuarrie, I. G., and B. Grafstein (1982) Protein synthesis and axonal transport in goldfish retinal ganglion cells during regeneration accelerated by a conditioning lesion. Brain Res. 251: 25-37.

McQuarrie, I. G., and R. J. Lasek (1989) Transport of cytoskeletal elements from parent axons into regenerating daughter axons. J. Neurosci. 9: 436-446.

Morris, J. R., and R. J. Lasek (1982) Stable polymers of the axonal cytoskeleton: the axoplasmic ghost. J. Cell Biol. 92: 192-198.

Moss, T. H., and S. J. Lewkowicz (1983) The axon reaction in motor and sensory neurones of mice studied by a monoclonal antibody marker of neurofilament protein. J. Neurol. Sic. 60:267-280.

Oblinger, M. M. (1985) Regeneration-associated changes in axonal microtubule protein transport in dorsal root ganglion cells of rat. Soc. Neurosci. Abstr. 11: 421.

Oblinger, M. M. (1987) Characterization of posttranslational processing of the mammalian high molecular weight neurofilament protein in vivo. J. Neurosci. 7:2510-2521.

Oblinger, M. M., and R. J. Lasek (1984) A conditioning lesion of the peripheral axons of dorsal ganglion cells accelerates regeneration of only their peripheral axons. J. Neurosci. 4: 1736-1744.

Oblinger, M. M., and R. J. Lasek (1985) Selective regulations of two axonal cytoskeletal networks in dorsal root ganglion cells. In $\mathrm{Neu}$ robiology: Molecular Biological Approaches to Understanding Neuronal Function and Development, P. O'Lague, ed., pp. 135-143, Liss, New York.

Oblinger, M. M., and R. J. Lasek (1988) Axotomy induced alterations in the synthesis and transport of neurofilaments and microtubules in dorsal root ganglion cells. J. Neurosci. 8: 1747-1758.

Pachter, J. S., and R. K. H. Liem (1984) The differential appearance of neurofilament triplet polypeptides in the developing rat optic nerve. Dev. Biol. 103: 200-210

Pickett, J., and M. M. Oblinger (1986) Developmental changes in the neuronal cytoskeleton of pyramidal tract neurons in golden hamsters: Biochemical and immunocytochemical studies. Soc. Neurosci. Abstr. 12: 1231

Price, D. L., and K. R. Porter (1972) The response of ventral horn neurons to axonal transection. J. Cell. Biol. 53: 24-37.

Weiss, P., and H. B. Hiscoe (1948) Experiments on the mechanism of nerve growth. J. Exp. Zool. 107: 315-395.

Willard, M. B., and C. Simon (1983) Modulations of neurofilament axonal transport during the development of rabbit retinal ganglion cells. Cell 35: 551-559.

Wong, J., and M. M. Oblinger (1987) Changes in neurofilament gene expression occur after axotomy of dorsal root ganglion neurons. An in situ hybridization study. Metab. Brain Dis. 2: 291-303.

Wujek, J. R., and R. J. Lasek (1983) Correlation of axonal regeneration and slow component $\mathrm{b}$ in two branches of a single axon. J. Neurosci. 3: 243-251.

Yamada, K. M., S. B. Spooner, and N. K. Wessels (1971) Ultrastructure and function of growth cones and axons of cultured nerve cells. J. Cell Biol. 49: 614-635. 